\title{
Eine perfekte Ergänzung
}

\section{Liebe Leserinnen und Leser,}

das Thema Investor Relations hat erheblich an Bedeutung gewonnen. Zu Zeiten eines funktionierenden Hausbankensystems war der Kontakt zum Kapitalmarkt auf einen Ansprechpartner konzentriert. Heute muss dagegen ein breites Bündel von Akteuren - Anteilseigner, potenzielle Investoren und Analysten - „gemanagt“ werden. Nicht nur die Zahl der Adressaten hat sich geändert, sondern auch die Heterogenität ihrer Ziele, von einer neutralen Einschätzung der wirtschaftlichen Situation des Unternehmens bis hin zu unterschwelligen Übernahmegelüsten. Insofern ist es nachvollziehbar, dass es ohne eine Professionalisierung nicht mehr geht. Damit ist ein weiterer Spieler mit direktem (Top-)Management-Kontakt an die Seite der Controller getreten.

Mit Letzteren haben die Investor-Relations-Verantwortlichen sehr viele Gemeinsamkeiten. Für beide stehen Ergebniszahlen im Mittelpunkt. Im Feld der Investor Relations geht es um das Verkaufen der Zahlen an die unterschiedlichen Adressaten. Auch den Controllern ist der Zahlenverkäufer ins Stammbuch geschrieben. Beide müssen ihre Zahlen erklären können; sie brauchen Überzeugungsfähigkeit ebenso wie ein Gespür dafür, was hinter den Fragen stecken könnte. Beide müssen mit dem Geschäft hinter den Zahlen vertraut sein. Übereinstimmend gilt für beide auch, dass sie ihre Ansprechpartner möglichst gut kennen sollten: deren persönliche Präferenzen, die von ihnen verfolgten Ziele, aber auch die Art, wie man mit ihnen am besten kommunizieren kann.

Neben diesen Übereinstimmungen gibt es aber natürlich auch Unterschiede zwischen Controlling und Investor Relations. Letztere sind primär nach außen gerichtet; sie decken die Schnittstelle zwischen Unternehmen und Kapitalmarkt ab. Controller richten ihren Blick dagegen primär ins Unternehmen hinein und bedienen die Schnittstellen zwischen den unterschiedlichen Managern. Ein weiterer Unterschied betrifft die Ausrichtung der Kommunikation: Investor Relations Manager wollen das Unternehmen möglichst gut am Kapitalmarkt verkaufen, für Controller dagegen stehen Neutralität,

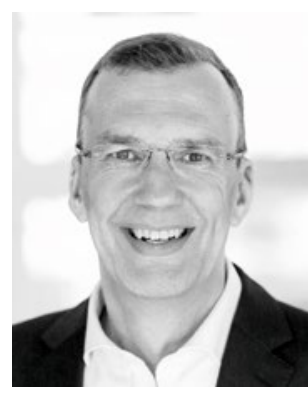

Utz Schäffer

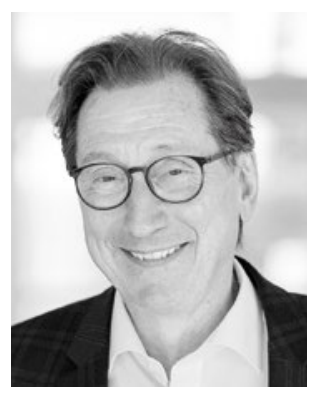

Jürgen Weber
Objektivität und Transparenz im Fokus, damit Manager mit den Zahlen und Fakten möglichst gut entscheiden können.

Dennoch: Die Gemeinsamkeiten überwiegen erheblich und insofern sollten Investor Relations und Controlling eng miteinander zusammenarbeiten. Beide können dabei die jeweils andere Perspektive auf das Geschäft sehr gut gebrauchen. Dem Controller, der die Wirkungen bestimmter Aktivitäten des Unternehmens in den Kapitalmarkt hinein nicht kennt, fehlt wichtiges Wissen ebenso wie dem Investor-RelationsVerantwortlichen, der nicht weiß, wie die Ergebniszahlen geschäftlich zustande gekommen sind. Beide sollten also schon zum eigenen Nutzen eng zusammenarbeiten - und manchmal braucht es auch des Gewichts beider zusammen, um zu hochfliegende Ideen des Vorstands zu erden!

Viel Spaß bei der Lektüre wünschen Ihnen
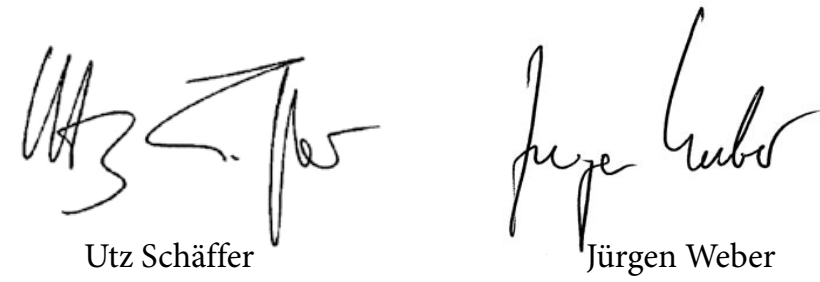